\title{
Congenital Cystic Adenomatoid Malformation of the Lung
}

National Cancer Institute

\section{Source}

National Cancer Institute. Congenital Cystic Adenomatoid Malformation of the Lung. NCI Thesaurus. Code C98892.

A congenital malformation that is present in the lungs of the newborn. It is characterized by a spectrum of lesions that range from single or multiple cysts to bulky overgrowth of bronchiole-like structures. Signs and symptoms include respiratory distress, recurrent pulmonary infections, dyspnea, and failure to thrive. 